\title{
Predictors of quality of life among youths in foster care-a 5-year prospective follow-up study
}

\author{
Marit Larsen $^{1}$ (D) Anouk Goemans $^{2}$ (D) $\cdot$ Valborg Baste $^{3}$ (D) $\cdot$ Tom F. Wilderjans $^{4,5,6}$ (D) Stine Lehmann ${ }^{1,7}$ (D)
}

Accepted: 12 September 2020 / Published online: 24 September 2020

(c) The Author(s) 2020

\begin{abstract}
Purpose Few studies have investigated possible predictors of positive outcomes for youths in foster care. The aim of this prospective follow-up study was to examine quality of life $(\mathrm{QoL})$ among youths in foster care and to assess whether contextual and child factors predicted QoL.

Methods Online questionnaires were completed by carers in Norway in 2012 (T1, $n=236$, child age 6-12 years) and by youths and carers in 2017 (T2, $n=405$, youth age 11-18 years). We received responses on 116 of the youths at both T1 and $\mathrm{T} 2$, and our final sample consisted of 525 youths with responses from T1 and/or T2. Child welfare caseworkers reported preplacement maltreatment and service use at $\mathrm{T} 1$. We assessed mental health and prosocial behavior at $\mathrm{T} 1$ by having carers complete the Strength and Difficulties Questionnaire and QoL at T2 with youth-reported KIDSCREEN-27. We analyzed the data using descriptive statistics, $t$-tests and multiple linear regressions, and we used multiple imputation to handle missing data.

Results Youths in foster care had lower QoL across all dimensions compared to a Swedish general youth sample. QoL scores among our sample were similar to Norwegian youths with ill or substance abusing parents and to European norm data. Youths reported the highest QoL scores on the parent relations and autonomy dimension. Male gender, younger age, kinship care and prosocial behavior five years earlier predicted higher QoL.

Conclusion Similar to other at-risk youths, youths in foster care seem to have lower QoL than the general Scandinavian population. Despite early adversities, they had good relations with their current carers. Adolescent girls seem especially vulnerable to low QoL and might need extra support to have good lives in foster care.
\end{abstract}

Keywords Quality of life · QoL · Foster care · Youth · Predictors · Prospective study

\section{Introduction}

Electronic supplementary material The online version of this article (https://doi.org/10.1007/s11136-020-02641-z) contains supplementary material, which is available to authorized users.

Marit Larsen

mala@norceresearch.no

1 Regional Centre for Child and Youth Mental Health and Child Welfare, NORCE Norwegian Research Centre, Nygårdstangen, Postbox 22, 5838 Bergen, Norway

2 Institute of Education and Child Studies, Leiden University, Leiden, The Netherlands

3 NORCE Norwegian Research Centre, Bergen, Norway

4 Methodology and Statistics Research Unit, Institute of Psychology, Faculty of Social and Behavioural
While a high prevalence of mental and physical health problems among youths in foster care is well documented [1, 2], less is known about youths in foster care that have good lives. Studies following youths in foster care over time are

Sciences, Leiden University, Pieter de la Court Building, Wassenaarseweg 52, 2333 AK Leiden, The Netherlands

5 Research Group of Quantitative Psychology and Individual Differences, Faculty of Psychology and Educational Sciences, KU Leuven, Tiensestraat 102, Box 3713, 3000 Leuven, Belgium

6 Leiden Institute for Brain and Cognition (LIBC), Leids Universitair Medisch Centrum (LUMC), 2300 RC Leiden, The Netherlands

7 Department of Health Promotion and Development, Faculty of Psychology, University of Bergen, Bergen, Norway 
needed to identify predictors of positive outcomes [3, 4]. Our study examined quality of life (QoL) among youths in foster care and compared them to other youth populations. Furthermore, we investigated whether contextual and child factors were predictive of $\mathrm{QoL}$ in adolescence.

QoL is a multidimensional construct that encompasses physical, emotional, mental, social and behavioral components of wellbeing and functioning as perceived by the individual [5]. As QoL is a subjective experience, the gold standard of assessment is self-report [6]. While research on QoL among youths in care is scarce, findings across countries suggest that youths in foster care [7] and youths in residential care [8-11] have a poorer QoL or health related quality of life (HRQoL) than youths in the general population (see Supplementary material 1 for an overview of studies on QoL and related terms cited in this introduction). However, some European studies found similar HRQoL [10] and subjective wellbeing [12] scores for youths in foster care and youths in the general population. Furthermore, youths in foster care report higher HRQoL [13], higher subjective wellbeing $[12,14]$, and more positive perceptions of their care situation [15] than youths in residential care. Thus, the current knowledge suggests that youths in foster care have a higher QoL than youths in residential care, but it is unclear whether they have lower QoL than youths in the general population. To gain knowledge about how foster care-related experiences specifically affect QoL, we need more studies comparing QoL between youths in foster care and youths reared in their family of origin.

Even though information about predictors of high QoL is crucial for helping more youths having a good life in foster care, there is a lack of studies following youths in foster care over time examining QoL. However, some cross-sectional studies exist that provide information about factors associated with QoL, HRQoL or subjective wellbeing, which makes them relevant to study as possible predictors. Across European countries, boys report higher QoL and HRQoL than girls in the general population [16, 17], and among youths in care [10, 18]. Furthermore, younger children report higher QoL and subjective wellbeing than adolescents in the general European population [17], and in care [14]. However, some studies of youths in care found no relation between HRQoL and gender [7] or age [7, 19], indicating that it is unclear how gender and age are related to QoL in this population.

Although findings are mixed [20], in general, maltreated children report lower HRQoL than children in the general population [21], and exposure to maltreatment is associated with lower QoL and HRQoL among youths in the general population $[16,22]$ and in residential care $[6$, 9]. Among young people in protective custody, experiences of family violence were related to lower HRQoL, while family instability (i.e., parental drug use, mental health problems and/or absent parents) was not [23]. These findings suggest that violent experiences may be especially relevant to study as a predictor of QoL among youths in care.

A positive association between placement stability and subjective wellbeing has been found among youths in care [14]. Furthermore, a Cochrane review indicated that youths in kinship care had higher wellbeing compared to youths in nonkinship foster care [24]. However, other studies found no association between HRQoL and the number of earlier placements [7] or the age of entry into care [23]. Thus, the relationship between placement characteristics and QoL is unclear.

Youths in contact with health care professionals had poorer QoL than youths without health care contact [25]. Youths in foster care have extensive service contact [26, 27], but there is a lack of studies investigating the relationship between service use and QoL for this group. Studies indicate that mental health problems were associated with low QoL and HRQoL among youth in care $[8,13,18]$. Good interpersonal relationships, however, contributed to subjective wellbeing among youths in care [14]. Overall, the findings indicate that service contact, mental health and social relationships might predict $\mathrm{QoL}$ among youths in foster care.

As most studies are cross-sectional, there is a need for studies following youths in foster care over time to identify predictors of QoL. This knowledge is necessary to inform services and informal networks about areas to focus on to enhance the wellbeing and positive development of youths in foster care. Furthermore, such knowledge may inform child welfare services (CWS) about how to organize placements to enable good lives. In addition, this information can benefit the whole population of youths in foster care, not only those with mental health problems. Lastly, there are substantial differences in how the child protective services are organized in different countries [28]. Therefore, it is uncertain how transferable the knowledge about QoL among youths in foster care is between countries. Moreover, we lack studies describing the QoL of youths in foster care from the Scandinavian setting.

The first aim of the current study was to examine QoL and its subdimensions among youths in foster care in Norway and to compare their QoL scores with the scores of youths with ill or substance abusing parents, Swedish youth, and European youth. Our second aim was to examine whether QoL of youths in foster care can be predicted by contextual factors (i.e., preplacement maltreatment, kin or nonkin foster care, years in current foster home and former service contact) and child factors (i.e., mental health problems, functional impairment, and prosocial behavior) when adjusted for gender and age. 


\section{Methods}

\section{Procedure and study sample}

The study sample is part of the research project "Young in Foster Care", where data were collected in two waves: wave one was between September 2011 and February 2012 (T1), and wave two was between October 2016 and March 2017 (T2). Eligible participants were youths in foster care born between 1999 and 2005 who were in a legally mandated placement in the Southeast of Norway and had lived in their current foster home for at least six months. The number of eligible participants was 396 at T1 and 740 at T2. Figure 1 provides a flowchart illustrating the data collection.

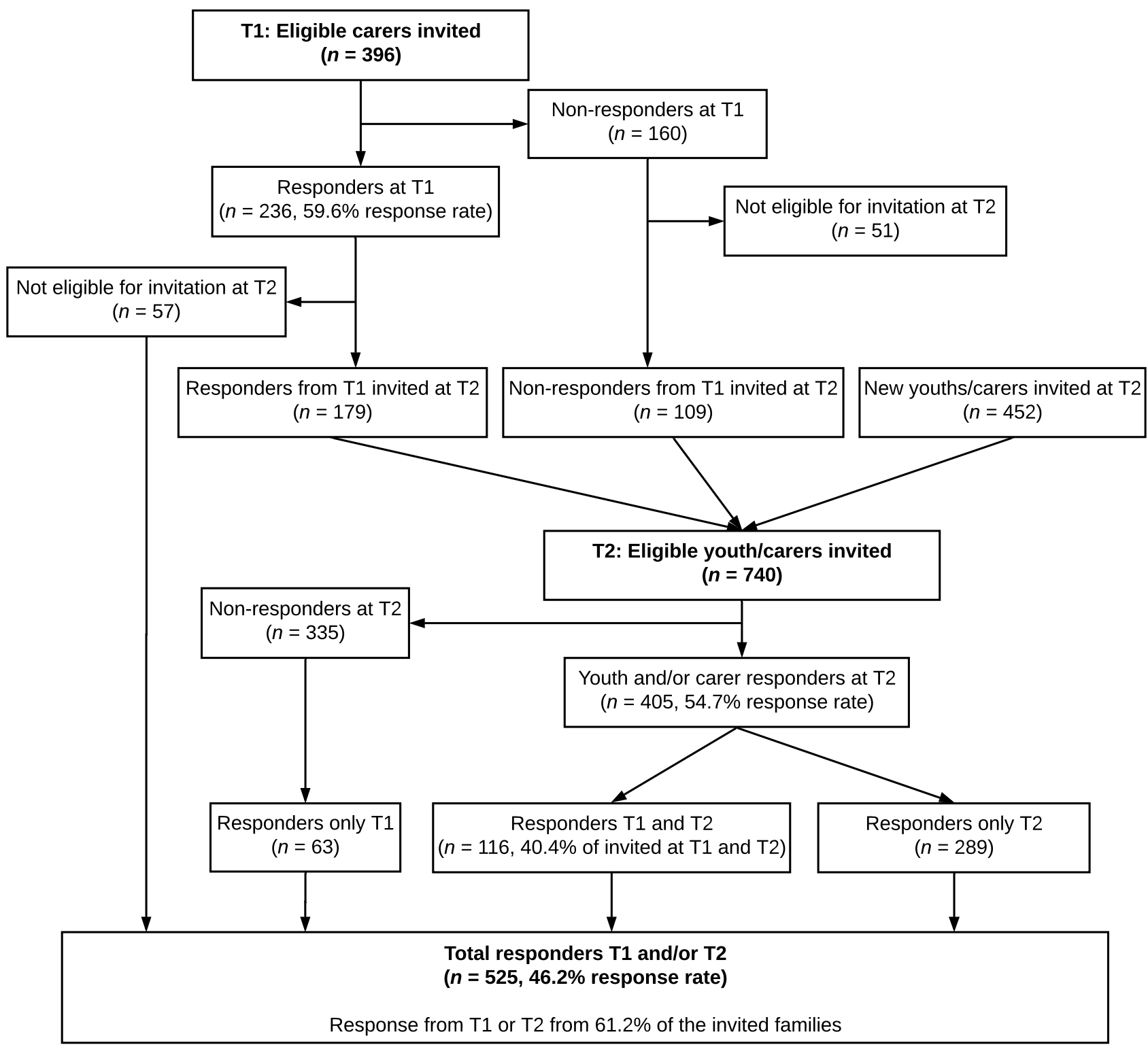

\footnotetext{
Note. Overview of responders and measures used at the different time points (T1 and T2)

T1: Foster parents reports on Child factors measured with the SDQ $(n=236)$

Caseworkers in the child welfare services reports on Maltreatment $(n=220)$ and Service contact $(n=218)$

T2: Youths reports on QoL measured with the KIDSCREEN27 $(n=298)$

Foster parents reports on Type of placement $(n=330)$

Caseworkers in the child welfare services reports on Gender $(n=523)$, Age $(n=525)$ and Years in current foster home $(n=467)$
}

Fig. 1 Flowchart of the data collection 
At T1, carers were invited to participate, while carers and youths were invited to participate at $\mathrm{T} 2$. We recruited participants via postal mail with an information letter describing the study and how to complete the survey, either online on a secure webpage or by telephone interview. We asked foster mothers, foster fathers and youths to complete the survey separately. We provided reminders by post and subsequent telephone contact. We compensated youths with a gift card of 300 NOK (approximately 38 USD) for participating. Carers were not compensated.

In this study, we included all youths who had a response from a carer at $\mathrm{T} 1(n=236)$ and/or a response from the youth $(n=303)$ and/or carer $(n=330)$ at T2 (total $n$ $\mathrm{T} 2=405)$. As we have $\mathrm{T} 1$ and $\mathrm{T} 2$ responses on 116 of the youths (i.e., $40.4 \%$ of the families invited at both $\mathrm{T} 1$ and T2), our finale sample consisted of 525 youths in foster care (46.2\% response rate; Fig. 1). We combined foster mothers $\left(N_{\mathrm{T} 1}=212, N_{\mathrm{T} 2}=285\right)$ and fathers $\left(N_{\mathrm{T} 1}=106, N_{\mathrm{T} 2}=120\right)$ into one group of informants for each wave. We used responses from foster fathers when the foster mother was a nonresponder; otherwise, we used responses from foster mothers.

\section{Ethics}

The Regional Committee for Medical and Health Research Ethics, Western Norway approved the study. The Norwegian Directorate for Children, Youth and Family Affairs provided exemptions from confidentiality for caseworkers and carers. In accordance with the Norwegian ethics requirement, oral consent is required from children aged 12 years or older. We described this in the invitation letter to youths and carers, and the youths were instructed that they could inform their carers if they did not want them to participate in the study.

\section{Measures}

\section{Demographic and contextual factors}

We collected information about gender, age and years in the current foster home from municipal CWS offices. We defined placement type as kinship care when carers at T2 were biologically related to their foster child. Preplacement maltreatment was measured at T1 with four custom-made yes/no questions asking the child's caseworker in CWS if the child had been exposed to or witnessed physical or emotional (i.e., threats, verbal punishment, harsh criticism or hostility) violence in the biological family before placement. We summed these variables into a new variable called "maltreatment", with scores ranging from 0 to 4 .

Service contact was measured at T1 with three custommade yes/no questions asking caseworkers if the child had ever been assessed by child and adolescent mental health services, educational psychological services, or habilitation services. We summed these questions into a new variable called "service contact", with scores ranging from 0 to 3 . We computed a sum score for youths when CWS had provided information about at least one of the services, and missing information on one or two providers was treated as 0 (i.e., no service contact).

\section{Child factors}

We measured child factors at T1 by having carers complete the Strengths and Difficulties Questionnaire (SDQ) [29]. This is a 25-item questionnaire consisting of five subscales, with five items on each subscale, assessing symptoms and impairments in the daily life of youths aged 4-17 years old. Each item is rated on a three-point scale ranging from 0-2. Four of the subscales measure symptoms and one subscale measures prosocial behavior (score range 0-10). A total difficulties score (range 0-40) is calculated by summing the symptom subscales. In addition, the SDQ contains an impact scale (range 0-10), referred to as "functional impairment", that measures distress and interference of symptoms in the youth's daily life [29]. The SDQ has shown satisfactory reliability and validity in general child populations [29, 30] and the predictive value of the SDQ completed by carers is supported for foster children [31]. In the current study, Cronbach's alpha for the total and subscales ranged from good to very good, as reported in Table 1.

\section{QoL}

We measured QoL at T2 with the KIDSCREEN-27 Quality of Life Questionnaire [25] a 27-item self-reported measure to assess five dimensions of QoL within the last week for youth aged 8-18 years old. The dimensions are physical wellbeing (e.g., Have you felt fit and well?), psychological wellbeing (e.g., Have you felt sad?), parent relations \& autonomy (e.g., Have your parent(s) treated you fairly?), peers \& social support (e.g., Have you had fun with your friends?), and school environment (e.g., Have you been able to pay attention?). Each item is scored on a five-point Likert scale ( $1=$ "never" or "not at all" to $5=$ "always" or "extremely"). The KIDSCREEN-10 questionnaire is embedded within the KIDSCREEN-27 questionnaire and consists of ten items that provide a single index of general QoL. In this study we utilized both the five dimensions of QoL from the KIDSCREEN-27 and the general QoL index calculated from the ten items in the KIDSCREEN-10 questionnaire. The reliability, discriminatory power, and validity of both instruments have been shown to be good [17, 25, 32]. The Norwegian version of the KIDSCREEN has shown good validity and reliability in the general population and in clinical samples [33]. Cronbach's alpha for both instruments in 
Table 1 Distribution of youth characteristics, contextual and child factors, and quality of life (QoL) among youths in foster care $(N=525)$

\begin{tabular}{|c|c|c|c|c|c|c|c|c|c|}
\hline & $N$ & $\%$ Missing $^{a}$ & $n$ & $\%$ & Mean & $S D$ & Min & $\operatorname{Max}$ & $\begin{array}{l}\text { Cron- } \\
\text { bach's } \\
\text { alpha }\end{array}$ \\
\hline Gender-boys & 523 & 0.4 & 285 & 54.5 & & & & & \\
\hline Age (in years) & 525 & 0 & & & 14.61 & 2.01 & 11.00 & 17.99 & \\
\hline Type of placement-Kinship care & 330 & 37.1 & 50 & 15.2 & & & & & \\
\hline Years in current foster home & 467 & 11.0 & & & 7.08 & 4.40 & 0.72 & 17.75 & \\
\hline Maltreatment at $\mathrm{T} 1$ & 220 & 58.1 & & & 0.88 & 1.23 & 0 & 4 & \\
\hline Physical violence & 220 & & 29 & 13.2 & & & & & \\
\hline Witnessed physical violence & 220 & & 59 & 26.8 & & & & & \\
\hline Emotional abuse & 220 & & 38 & 17.3 & & & & & \\
\hline Witnessed emotional abuse & 220 & & 67 & 30.5 & & & & & \\
\hline Service contact at $\mathrm{T} 1$ & 218 & 58.5 & & & 1.06 & 0.95 & 0 & 3 & \\
\hline CAMHS & 209 & & 96 & 45.9 & & & & & \\
\hline Education psychology service & 205 & & 108 & 52.7 & & & & & \\
\hline Habilitation service & 192 & & 26 & 13.5 & & & & & \\
\hline \multicolumn{10}{|c|}{ Foster parent reported child factors at $\mathrm{T} 1$} \\
\hline Total difficulties & 236 & 55.0 & & & 15.24 & 7.94 & 0 & 35 & .88 \\
\hline Prosocial behavior & 236 & 55.0 & & & 6.84 & 2.30 & 0 & 10 & .77 \\
\hline Functional impairment & 236 & 55.0 & & & 2.69 & 2.74 & 0 & 10 & .80 \\
\hline \multicolumn{10}{|l|}{ T-scores of the QoL dimensions } \\
\hline General QoL & 298 & 43.2 & & & 47.99 & 11.82 & 15.88 & 83.81 & .87 \\
\hline Physical wellbeing & 298 & 43.2 & & & 46.30 & 13.21 & 20.70 & 73.20 & .87 \\
\hline Psychological wellbeing & 297 & 43.4 & & & 49.33 & 13.70 & 17.56 & 73.53 & .92 \\
\hline Parent relations and autonomy & 297 & 43.4 & & & 52.80 & 13.01 & 1.75 & 74.39 & .89 \\
\hline Social support and peers & 296 & 43.6 & & & 50.22 & 11.63 & 23.62 & 66.34 & .86 \\
\hline School environment & 298 & 43.2 & & & 48.35 & 11.98 & 16.28 & 71.00 & .88 \\
\hline
\end{tabular}

a\% missing's are provided for the variables used in further analyses the current study ranged from good to very good (Table 1). For both measures, the raw scores were computed into t-scores using a mean of 50 and a standard deviation of 10 (i.e., the mean and SD of the norm population), adopting the scoring algorithms provided by the KIDSCREEN group [25]. We applied confirmatory factor analysis (CFA) to test whether the established five-factor structure of KIDSCREEN-27 fitted our data. The five-factor structure showed an acceptable fit to our data $(\mathrm{CFI}=0.88, \mathrm{RMSEA}=0.09)$ and was improved $(\mathrm{CFI}=0.90, \mathrm{RMSEA}=0.08)$ by allowing items six and seven of the parent relations and autonomy dimension to correlate.

\section{Analyses}

Descriptive statistics for gender, age (at T2), contextual and child factors, and QoL are presented as percentages, means (M), standard deviations (SD), minimum and maximum values. We compared the T1 values of gender, age, maltreatment, service use, and child factors between T1-only responders and responders at both $\mathrm{T} 1$ and $\mathrm{T} 2$ using twosample t-tests, and found no differences between the groups.
We examined the correlations between general QoL, the five QoL dimensions, and all predictors. No problems with multicollinearity were indicated between variables included in the same analysis, with functional impairment and total difficulties having the highest correlation (0.73).

We conducted two-sample $t$-tests to compare the $t$-scores on the five dimensions of QoL against the $t$-scores in a Swedish general population sample [34], a Norwegian sample of youths with ill or substance abusing parents (at-risk Norwegian youths [35]) and European norm data from youths aged 12-18 [25]. We used the same test to compare the general QoL scores in our sample to Swedish [32] and European norm data [25]. We calculated the Cohen's $d$ effect sizes of the differences between the groups by dividing the mean difference by the pooled standard deviation, where $d=0.2$ can be considered a 'small' effect size, $d=0.5$ a 'medium' effect size and $d=0.8$ a 'large' effect size [36].

To examine possible predictors of QoL, we conducted separate linear regression analyses for general QoL and the five QoL dimensions. In each regression analysis, we added the predictors stepwise. The covariates gender and age were added first. Second, contextual factors were added (i.e., 
maltreatment, service contact, type of placement and years in current foster home). Last, the child factors (i.e., total difficulties, prosocial behavior, and functional impairment) were added to the model. We used multiple imputation to handle missing data. Multiple imputation models were fitted separately for general QoL and the five QoL dimensions and included all predictors from the full regression model. We imputed missing values on both predictor and outcome variables. In both imputation models, we used the sum scores of the variables, created 30 imputed datasets and pooled the results from the regression analyses into overall estimates. To investigate the effect of the missing data on the obtained results, the regression models were also fit with full information maximum likelihood (FIML) to address missing data. These additional analyses yielded similar results (see Supplementary Tables 1 and 2) which supports the validity of our findings.

Descriptive statistics were calculated using IBM SPSS Statistics 24 [37]. We conducted multiple linear regressions in R [38], and multiple imputation models were fitted with the MICE package [39]. We also performed the CFA and regression analyses with FIML in R using the Lavaan package [40]. The significance level was set to 0.05 .

\section{Results}

As can be seen in Table 1, our sample consisted of $54.5 \%(n=285$, total $n=523)$ boys and had a mean age of $14.61(\mathrm{SD}=2.01)$. On average, they had lived 7.08 years $(\mathrm{SD}=4.40)$ in their current foster home, and $15.2 \%(n=50$, total $n=330)$ lived in kinship care. The foster youths had experienced, on average, less than one $(M=0.88, \mathrm{SD}=1.23)$ type of maltreatment with witnessing emotional abuse as the most common type $30.5 \%$, $n=67$, total $n=220)$. Most youths had been in contact with one service at $\mathrm{T} 1(M=1.06, \mathrm{SD}=0.95)$. The mean reported total difficulties at $\mathrm{T} 1$ was $15.24(\mathrm{SD}=7.94)$, and $58.9 \%(n=139$, total $n=236)$ of the responders scored at or above the suggested cut off score of 13 [31] for being in the clinical range of mental health problems for this group.

\section{QoL and comparison of scores to other youth samples}

General QoL had high correlations to the five QoL dimensions, and the highest was with psychological wellbeing (0.85; Supplementary Table 3). The highest QoL scores were reported on the parent relations and autonomy dimension $(M=52.8)$, while the lowest scores were on physical wellbeing ( $M=46.3$; Table 2). Compared to the Swedish general youth population, the youths in our sample had lower general QoL $(d=-0.36, p<0.001)$ and lower scores on all QoL dimensions with small or medium effect sizes. Compared to the at-risk Norwegian youths, the youths in foster care reported lower scores on the school environment dimension $(d=-0.23, p=0.009)$ but higher scores on the parent relations and autonomy dimension $(d=0.18$, $p=0.041)$. Compared to European norm data, the youths in our sample had higher scores on the parent relations and autonomy dimension $(d=0.29, p<0.001)$ but lower physical wellbeing $(d=-0.20, p<0.001)$. The effect sizes of the differences between our sample and the Norwegian at-risk youths and European norm data were small.

\section{Predictors of general QoL}

Male gender and younger age predicted higher general QoL in all steps of the regression analyses (Table 3). Living in kinship care was predictive of higher general QoL compared to living in nonkin care in step two $(B=5.15,95 \%$ CI $[0.79$, 9.51], $p=0.022$ ), but this relationship was not significant when adjusting for child factors in step 3 ( $B=3.32,95 \% \mathrm{CI}$ $[-1.17,7.80], p=0.143)$. Prosocial behavior was predictive of higher general QoL $(B=1.34,95 \%$ CI $[0.36,2.32]$, $p=0.009$ ). The full model explained $33 \%$ of the variance in general QoL.

\section{Predictors of the five dimensions of QoL}

For all five QoL dimensions, male gender and younger age predicted higher QoL in all steps of the analyses (Table 4). More maltreatment experiences $(B=2.23,95 \%$ CI $[0.09$, 4.37], $p=0.042)$, kinship care $(B=4.82,95 \%$ CI [0.11, 9.52], $p=0.045)$, and more prosocial behavior $(B=1.53$, 95\% CI $[0.40,2.66], p=0.010)$ predicted higher physical wellbeing. More prosocial behavior was also predictive of higher psychological wellbeing $(B=1.39,95 \%$ CI [0.04, 2.73], $p=0.044)$. Living in kinship care was predictive of higher scores on the parent relations and autonomy dimension compared to living in nonkin care $(B=6.14,95 \%$ CI $[1.11,11.17], p=0.018)$. The full model ranged from explaining $40 \%$ of the variance in physical wellbeing to $12 \%$ of the variance in the social support and peers dimension.

\section{Discussion}

The youths in foster care had lower general QoL and lower QoL across all dimensions than Swedish youths in the general population. However, compared to at-risk Norwegian youths and European norm data, the scores were similar on most dimensions. To our knowledge, this is the first prospective study to investigate the predictors of QoL among youths in foster care. Male gender, younger age, living in kinship 


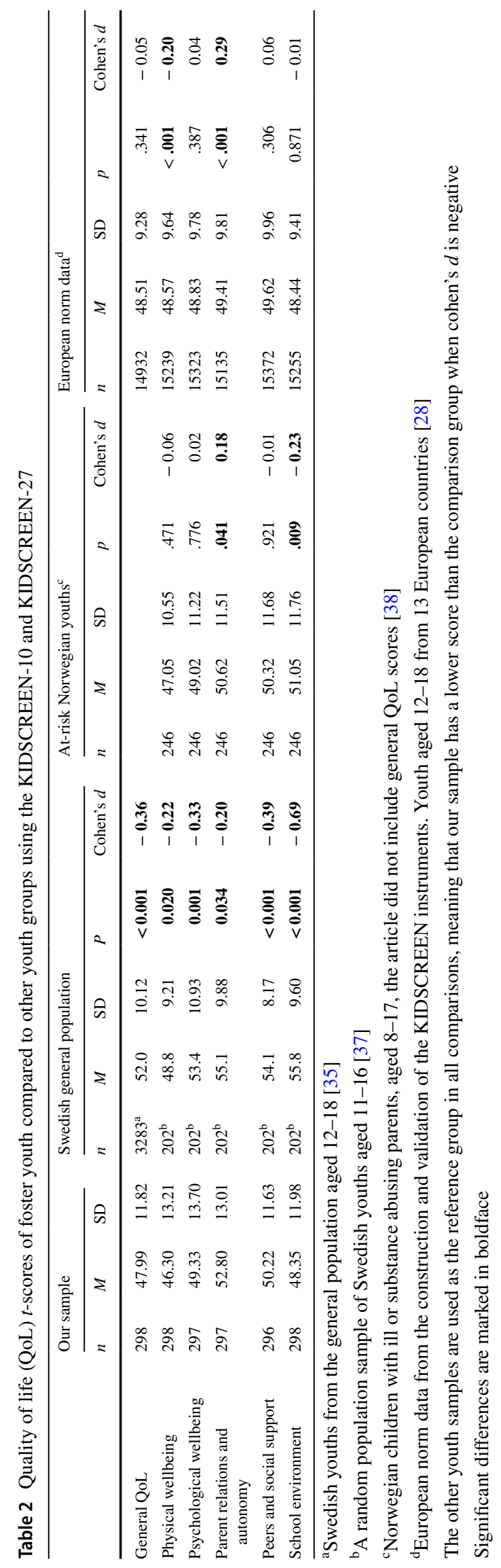


care and more prosocial behavior five years earlier predicted higher QoL.

Our finding that youths in foster care had lower QoL than Swedish youths from the general population [32, 34] is in line with findings from Australia, where youths in foster care had lower HRQoL on most dimensions compared to the general population [7]. However, this contrast to a Serbian study, which observed no differences in HRQoL between youths in foster care and the general population [10]. The youths in our sample had similar QoL scores on most dimensions compared to European norm data. Sizeable differences in general QoL are observed between countries [32] and because Scandinavia has better health status and higher subjective wellbeing than most European countries [41], it seems plausible that Scandinavian youths will have higher QoL levels, as indicated by the high scores in the Swedish norm data.

We found that youths in foster care had lower physical wellbeing than the Swedish general population sample [34]

Table 3 Associations between general quality of life (QoL) and contextual and child factors, adjusted for gender and age $(N=525)$

\begin{tabular}{|c|c|c|c|}
\hline & \multicolumn{3}{|c|}{ General QoL } \\
\hline & $\mathrm{adj}^{2}$ & $B$ & $95 \% \mathrm{CI}$ \\
\hline Step 1: covariates & 0.17 & & \\
\hline Gender $^{\mathrm{a}}$ & & $\mathbf{7 . 4 0}$ & {$[4.99,9.82]$} \\
\hline Age (years) & & -1.55 & {$[-2.14,-0.96]$} \\
\hline Step 2: added contextual factors & 0.21 & & \\
\hline Gender $^{\mathrm{a}}$ & & 7.96 & {$[5.48,10.44]$} \\
\hline Age (years) & & -1.48 & {$[-2.08,-0.87]$} \\
\hline Maltreatment ${ }^{\mathrm{b}, \mathrm{d}}$ & & -0.12 & {$[-2.18,1.94]$} \\
\hline Service contact ${ }^{\mathrm{d}}$ & & -0.93 & {$[-3.37,1.50]$} \\
\hline Type of placement ${ }^{\mathrm{c}}$ & & 5.15 & {$[0.79,9.51]$} \\
\hline Years in current foster home & & 0.06 & {$[-0.27,0.38]$} \\
\hline Step 3: added child factors & 0.33 & & \\
\hline Gender $^{\mathrm{a}}$ & & 7.71 & {$[5.06,10.36]$} \\
\hline Age (years) & & -1.33 & {$[-1.94,-0.73]$} \\
\hline Maltreatment ${ }^{\mathrm{b}, \mathrm{d}}$ & & 0.20 & {$[-1.78,2.18]$} \\
\hline Service contact ${ }^{\mathrm{d}}$ & & 0.28 & {$[-2.64,3.20]$} \\
\hline Type of placement ${ }^{\mathrm{c}}$ & & 3.32 & {$[-1.17,7.80]$} \\
\hline Years in current foster home & & -0.17 & {$[-0.55,0.20]$} \\
\hline Total difficulties ${ }^{\mathrm{d}}$ & & -0.30 & {$[-0.80,0.20]$} \\
\hline Prosocial behavior $^{\mathrm{d}}$ & & 1.34 & {$[0.36,2.32]$} \\
\hline Functional impairment $^{\mathrm{d}}$ & & 0.34 & {$[-0.64,1.32]$} \\
\hline
\end{tabular}

${ }_{a d j} R^{2}$ Adjusted $R$ squared, $B$ beta values (unstandardized coefficient), $C I$ confidence interval

${ }^{\mathrm{a}}$ Girls are the reference group

${ }^{\mathrm{b}}$ A sum score of four maltreatment items (range 0-4)

${ }^{\mathrm{c}}$ Nonkinship care is the reference group

${ }^{\mathrm{d}}$ Variable was measured at $\mathrm{T} 1$

Significant associations are marked in boldface and the European norm data [25], but similar levels to the atrisk Norwegian youths [35]. These findings imply that physical wellbeing and health are important to assess and target in interventions for at-risk youths. Our sample reported lower scores on the school environment dimension compared to the at-risk Norwegian youths, which might be a consequence of youths in foster care changing schools more often than other youths [42]. Youths in foster care reported the highest scores on the parent relations and autonomy dimension. These scores were lower than the scores from the Swedish general population sample but higher than the scores from European norm data and at-risk Norwegian youths. These findings suggest that despite their often detrimental care experiences, youths moved into adequate care conditions often form good relationships with their new caregivers. The effect sizes for the differences found between the compared youth groups ranged from 0.18 to 0.69 , which are considered as small to medium according to Cohen [36]. However, even small differences may have substantial impact when they affect many people, as is the case for youths in foster care.

Male gender and younger age predicted higher QoL, which is in line with findings from the general population $[16,17]$ and from youths in care $[10,14]$. While girls in the general European population reported higher scores on the peers and social support and school environment dimensions compared to boys [17], our results showed that girls had lower QoL across all dimensions. This might indicate that girls are especially vulnerable to the stressors of preplacement maltreatment and moving into foster care, and may need extra support to facilitate a positive development.

Living in kinship care predicted higher general QoL compared to living in nonkinship care, but only prior to controlling for the child factors. This might indicate that youths in kinship care report higher general QoL because of better mental health. This is in line with findings from Winokur et al. [24] that children in kinship care had higher wellbeing and fewer mental health disorders compared to children in nonkinship care. However, living in kinship care was predictive of higher physical wellbeing and higher scores on the parent relations and autonomy dimension compared to living in nonkinship care, even after adjusting for child factors, indicating that youths in kinship care have better physical health and better relations with caregivers. One might speculate that the CWS more often places youths with good health and good relations with their extended family in kinship care; alternatively, when the contact between youths and kinship caregivers is of high quality, this placement form supports contact with the biological family and their local community, which could lead to positive outcomes.

In contrast to previous findings that exposure to family violence was associated with lower HRQoL [23], we found that previous maltreatment predicted higher physical wellbeing. However, the effect was small and only present when 


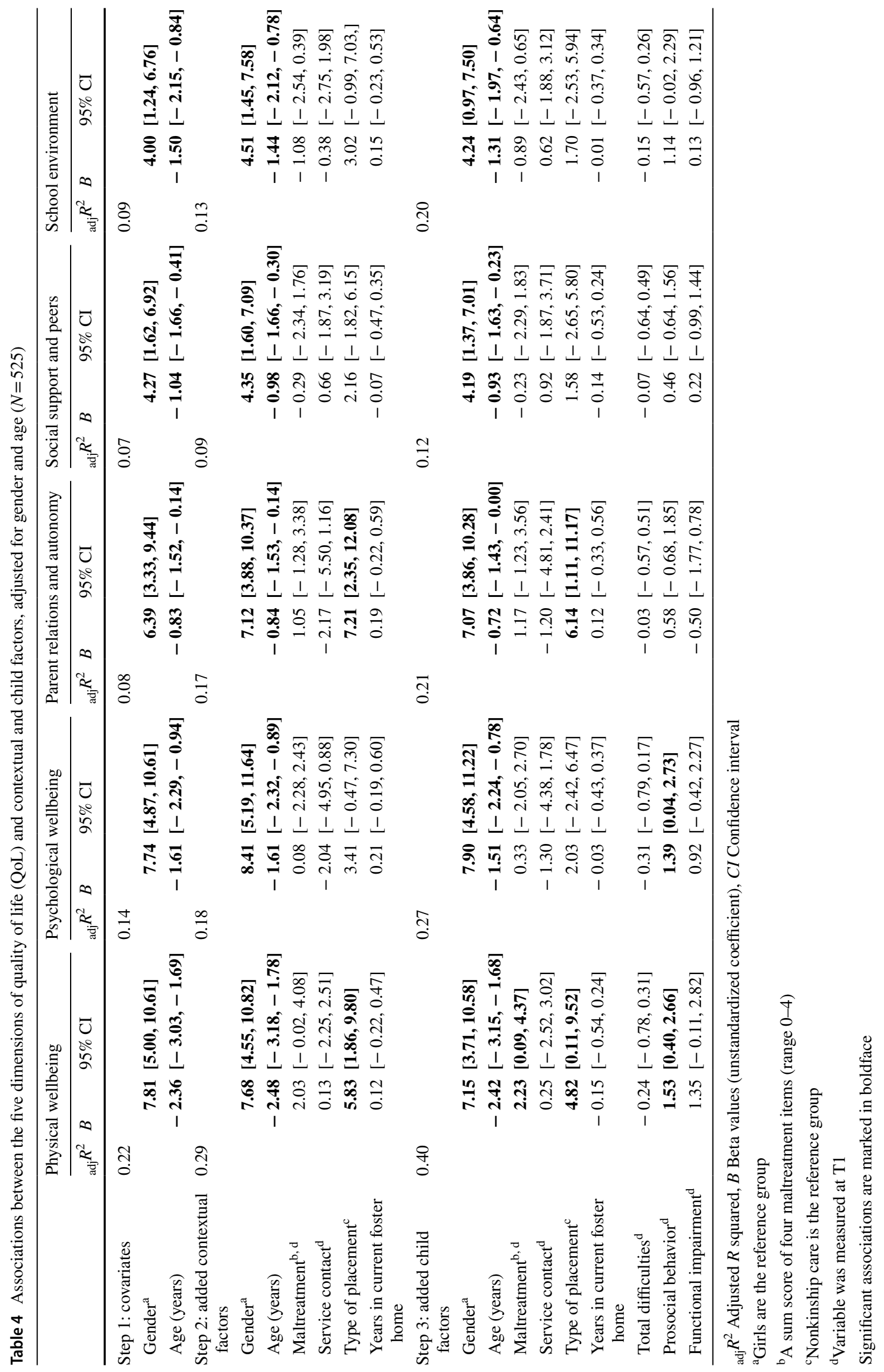


controlling for the child factors; thus, further research on the relation between maltreatment and QoL among youths in foster care is warranted.

Neither years in the current foster home nor previous service contact was predictive of QoL, which contrasts to findings that youths with longer stays in the same placement reported higher subjective wellbeing [14]. However, the youths in our sample had lived seven years in their current foster home on average, which may limit our opportunity to discover possible negative effects of short stays and frequent moves on QoL. Moreover, mental health and functional impairment five years earlier did not predict QoL, indicating that childhood mental health problems do not necessarily lead to poor QoL among adolescents in foster care. This result was surprising, as studies have found associations between mental health and QoL [18] and that youths in foster care showed stable trajectories of mental health [43]. Our findings might be a consequence of youths receiving effective mental health services and/or positive development processes in the foster home. Prosocial behavior five years earlier predicted general QoL, physical wellbeing, and psychological wellbeing, indicating that building social skills among youths in foster care might be one way to enhance future QoL.

The full model of predictors explained $33 \%$ of the variance in general QoL; gender and age contributed to roughly half of the explained variance, indicating that these characteristics are important determinants of QoL. The explained variance varied between the QoL dimensions, with the included predictors having the greatest effect on physical wellbeing (40\%) and the weakest effect on the social support and peers dimension (12\%).

\section{Strengths and limitations}

As this study used a QoL instrument with good crosscultural validity [25], we have been able to compare QoL among youths in foster care to QoL in other youth populations. We have a fairly large sample of high-risk youths that are difficult to recruit and challenging to follow over time due to instability in their living arrangements. Consequently, a limitation of our study is that we have missing data between $\mathrm{T} 1$ and $\mathrm{T} 2$ that is mainly due to changes in the youths living arrangements making them ineligible for recruitment at T2 (e.g., adoption, moved within the last six months, moved to an institution or reunited with biological parents). The response rate of invited youths at $\mathrm{T} 2$ was somewhat low $(41.9 \%)$, which could influence the generalizability of our results. However, there were no differences in baseline measures for families lost to follow-up, and we have no reason to assume that missing data were related to QoL. Furthermore, we used multiple imputation to handle the missing data, which is preferable over listwise and pairwise deletion, as it results in more statistical power, gives unbiased results when data are missing at random and less biased results than other methods when data are not missing at random [44].

In our study maltreatment was reported by caseworkers, which could influence the accuracy of the measure, as caseworkers do not have full information about children's experiences. We considered to include the SDQ sub dimensions externalization and internalization problems as predictors in our analyses, but as these dimensions where highly correlated to total difficulties and to each other (data not shown) we only included total difficulties in the final analyses. We had no information on factors such as intelligence and socio economic status and future studies of QoL among youths in foster care ought to include such variables.

\section{Conclusions}

Youths in foster care had lower QoL than Scandinavian youths in general, indicating that these youths need more support to enhance their QoL. The relatively high scores on the parent relations and autonomy dimension implies that these youths have supportive relationships with their carers. Our finding of higher QoL among boys and among younger youth suggests that adolescent girls might need extra support to have good lives. Furthermore, higher physical wellbeing and better carer-relations among youths in kinship care lend support to the ongoing preference for kinship placements when the extended family can provide adequate care. Last, our results indicate that it is important to build and strengthen relational resources among children who have experienced detrimental care conditions.

Acknowledgements We are grateful for the participation from youths in foster care and their foster parents in this study. To secure ethical and relevant research we have been cooperating with the user organizations Norwegian Foster Care Association (NFF) and the national association for children in the child protection system (LFB) in the planning and implementation of this study.

Author contributions ML contributed in the conception of the research questions and the data collection at $\mathrm{T} 2$, and was the main contributor in performing statistical analyses, and writing of the manuscript. AG, VB and TFW assisted in the choice of analyses and in the interpretation of the results, and contributed in revising and critically commenting on drafts. SL led the conception of the research questions and the design of the study and the data collection, and contributed in drafting and revising the manuscript. All authors read and approved the final manuscript.

Funding Open Access funding provided by NORCE Norwegian Research Centre AS. Marit Larsen is founded by Stiftelsen Dam (Grant Number 149980). The project and Stine Lehmann is funded by the Norwegian Research Council (Grant Number 256598). The funding bodies did not have any role in the design, analysis, or writing of this manuscript. 
Data availability Access to data is restricted by Norwegian law on medical and health related research. Information about the data and analysis is available from corresponding author Marit Larsen on request.

Code availability Code is available from Marit Larsen upon request.

\section{Compliance with ethical standards}

Conflicts of interest The authors declare that they have no competing interests.

Ethical approval The Regional Committee for Medical and Health Research Ethics, Western Norway approved the study. The Norwegian Directorate for Children, Youth and Family Affairs provided exemptions from confidentiality for caseworkers and carers. In accordance with the Norwegian ethics requirement, oral consent is required from children aged 12 years or older. This was described in the invitation letter to youths and carers, and the youths were instructed that they could inform their carers if they did not want them to participate in the study.

Open Access This article is licensed under a Creative Commons Attribution 4.0 International License, which permits use, sharing, adaptation, distribution and reproduction in any medium or format, as long as you give appropriate credit to the original author(s) and the source, provide a link to the Creative Commons licence, and indicate if changes were made. The images or other third party material in this article are included in the article's Creative Commons licence, unless indicated otherwise in a credit line to the material. If material is not included in the article's Creative Commons licence and your intended use is not permitted by statutory regulation or exceeds the permitted use, you will need to obtain permission directly from the copyright holder. To view a copy of this licence, visit http://creativecommons.org/licenses/by/4.0/.

\section{References}

1. Bronsard, G., Alessandrini, M., Fond, G., Loundou, A., Auquier, P., Tordjman, S., et al. (2016). The prevalence of mental disorders among children and adolescents in the child welfare system: a systematic review and meta-analysis. Medicine, 95(7), e2622.

2. Kling, S., Vinnerljung, B., \& Hjern, A. (2016). Somatic assessments of 120 Swedish children taken into care reveal large unmet health and dental care needs. Acta Paediatrica, 105(4), 416-420. https://doi.org/10.1111/apa.13304.

3. Goemans, A., van Geel, M., \& Vedder, P. (2015). Over three decades of longitudinal research on the development of foster children: a meta-analysis. Child Abuse \& Neglect, 42, 121-134.

4. Backe-Hansen, E., Egelund, T., \& Havik, T. (2010). Barn og unge i fosterhjem-en kunnskapsstatus [Children and youths in foster care - status of the current knowledge]. Oslo: Norsk institutt for forskning om oppvekst, velferd og aldring (NOVA)

5. Ravens-Sieberer, U., Herdman, M., Devine, J., Otto, C., Bullinger, M., Rose, M., et al. (2014). The European KIDSCREEN approach to measure quality of life and well-being in children: development, current application, and future advances. Quality of Life Research, 23(3), 791-803. https://doi.org/10.1007/s11136-013-0428-3.

6. Greger, H. K., Myhre, A. K., Lydersen, S., \& Jozefiak, T. (2016). Child maltreatment and quality of life: a study of adolescents in residential care. Health and Quality of Life Outcomes, 14(1), 74. https://doi.org/10.1186/s12955-016-0479-6.
7. Carbone, J. A., Sawyer, M. G., Searle, A. K., \& Robinson, P. J. (2007). The health-related quality of life of children and adolescents in home-based foster care. Quality of Life Research, 16(7), 1157-1166. https://doi.org/10.1007/s11136-007-9227-z.

8. Bronsard, G., Lançon, C., Loundou, A., Auquier, P., Rufo, M., Tordjman, S., et al. (2013). Quality of life and mental disorders of adolescents living in French residential group homes. Child Welfare, 92(3), 47-71.

9. Seiler, A., Kohler, S., Ruf-Leuschner, M., \& Landolt, M. A. (2016). Adverse childhood experiences, mental health, and quality of life of Chilean girls placed in foster care: an exploratory study. Psychological Trauma: Theory, Research, Practice, and Policy, 8(2), 180-187. https://doi.org/10.1037/tra0000037.

10. Damnjanović, M., Lakić, A., Stevanović, D., Jovanović, A., Jančić, J., Jovanović, M., et al. (2012). Self-assessment of the quality of life of children and adolescents in the child welfare system of Serbia. VojnosanitetskiPregled, 69(6), 469-474.

11. Jozefiak, T., \& Kayed, S. N. (2015). Self- and proxy reports of quality of life among adolescents living in residential youth care compared to adolescents in the general population and mental health services. Health and Quality of Life Outcomes, 13(1), 104. https://doi.org/10.1186/s12955-015-0280-y.

12. Llosada-Gistau, J., Casas, F., \& Montserrat, C. (2017). What matters in for the subjective well-being of children in care? Child Indicators Research, 10(3), 735-760. https://doi.org/10.1007/ s12187-016-9405-z.

13. Damnjanovic, M., Lakic, A., Stevanovic, D., \& Jovanovic, A. (2011). Effects of mental health on quality of life in children and adolescents living in residential and foster care: a cross-sectional study. Epidemiology and Psychiatric Sciences, 20(3), 257-262. https://doi.org/10.1017/S2045796011000291.

14. Llosada-Gistau, J., Casas, F., \& Montserrat, C. (2019). Factors influencing the subjective well-being of adolescents in out-ofhome care. A mixed method study. Applied Research in Quality of Life. https://doi.org/10.1007/s11482-019-9708-6.

15. Li, D., Chng, G. S., \& Chu, C. M. (2019). Comparing long-term placement outcomes of residential and family foster care: a metaanalysis. Trauma, Violence, \& Abuse, 20(5), 653-664. https://doi. org/10.1177/1524838017726427.

16. Jernbro, C., Tindberg, Y., Lucas, S., \& Janson, S. (2015). Quality of life among Swedish school children who experienced multitype child maltreatment. Acta Paediatrica, 104(3), 320-325. https:// doi.org/10.1111/apa.12873.

17. Ravens-Sieberer, U., Auquier, P., Erhart, M., Gosch, A., Rajmil, L., Bruil, J., et al. (2007). The KIDSCREEN-27 quality of life measure for children and adolescents: psychometric results from a cross-cultural survey in 13 European countries. Quality of Life Research, 16(8), 1347-1356. https://doi.org/10.1007/s1113 6-007-9240-2.

18. Gander, T., Boonmann, C., Fegert, J. M., Kölch, M., Schmeck, K., Di Gallo, A., et al. (2019). Predictive factors for changes in quality of life among children and adolescents in youth welfare institutions. Social Psychiatry and Psychiatric Epidemiology, 54, $1575-1586$

19 Jozefiak, T., Kayed, N. S., Ranøyen, I., Greger, H. K., Wallander, J. L., \& Wichstrøm, L. (2017). Quality of life among adolescents living in residential youth care: do domain-specific self-esteem and psychopathology contribute? Quality of Life Research, 26, 2619-2631.

20. Weber, S., Jud, A., Landolt, M. A., \& Goldbeck, L. (2017). Predictors of health-related quality of life in maltreated children and adolescents. Quality of Life Research, 26(10), 2717-2727. https ://doi.org/10.1007/s11136-017-1615-4.

21. Lanier, P., Kohl, P. L., Raghavan, R., \& Auslander, W. (2015). A preliminary examination of child well-being of physically abused and neglected children compared to a normative 
pediatric population. Child Maltreatment, 20(1), 72-79. https:// doi.org/10.1177/1077559514557517.

22. Weber, S., Jud, A., \& Landolt, M. A. (2016). Quality of life in maltreated children and adult survivors of child maltreatment: a systematic review. Quality of Life Research, 25(2), 237-255. https ://doi.org/10.1007/s11136-015-1085-5.

23. Beal, S. J., Wingrove, T., Mara, C. A., Lutz, N., Noll, J. G., \& Greiner, M. V. (2019). Childhood adversity and associated psychosocial function in adolescents with complex trauma. Child \& Youth Care Forum, 48(3), 305-322. https://doi.org/10.1007/s1056 6-018-9479-5.

24. Winokur, M., Holtan, A., \& Batchelder, K. E. (2014). Kinship care for the safety, permanency, and well-being of children removed from the home for maltreatment. Cochrane Database of Systematic Reviews. https://doi.org/10.1002/14651858.CD006546.pub3.

25. Ravens-Sieberer, U., Gosch, A., Erhart, M., Rueden, U., Nickel, J., Kurth, B. M., et al. (2006). The Kidscreen questionnaires: quality of life questionnaires for children and adolescents; handbook. Lengerich: Pabst Science Publ.

26. Larsen, M., Baste, V., Bjørknes, R., Myrvold, T., \& Lehmann, S. (2018). Services according to mental health needs for youth in foster care?-A multi-informant study. BMC Health Services Research, 18(1), 634.

27. Minnis, H., Everett, K., Pelosi, A. J., Dunn, J., \& Knapp, M. (2006). Children in foster care: mental health, service use and costs. European Child \& Adolescent Psychiatry, 15(2), 63-70. https://doi.org/10.1007/s00787-006-0452-8.

28. Gilbert, N., Parton, N., \& Skivenes, M. (Eds.). (2011). Child protection systems: international trends and orientations. USA: Oxford University Press.

29. Goodman, R. (1999). The extended version of the Strengths and difficulties questionnaire as a guide to child psychiatric caseness and consequent burden. Journal of Child Psychology and Psychiatry, 40(5), 791-799. https://doi.org/10.1111/1469-7610.00494.

30. Goodman, R. (2001). Psychometric properties of the strengths and difficulties questionnaire. Journal of the American Academy of Child \& Adolescent Psychiatry. https://doi.org/10.1097/00004 583-200111000-00015.

31. Lehmann, S., Heiervang, E. R., Havik, T., \& Havik, O. E. (2014). Screening foster children for mental disorders: properties of the strengths and difficulties questionnaire. PLoS One, 9(7), e102134. https://doi.org/10.1371/journal.pone.0102134.

32. Ravens-Sieberer, U., Erhart, M., Rajmil, L., Herdman, M., Auquier, P., Bruil, J., et al. (2010). Reliability, construct and criterion validity of the KIDSCREEN-10 score: a short measure for children and adolescents' well-being and health-related quality of life. Quality of Life Research, 19(10), 1487-1500. https://doi. org/10.1007/s11136-010-9706-5.

33. Haraldstad, K., \& Richter, J. (2014). Måleegenskaper ved den norske versjonen av KIDSCREEN [Measurement properties of the Norwegain version of KIDSCREEN]. PsykTestBarn: måleegenskaper ved tester og kartleggingsverkt $\phi y$.

34. Berman, A. H., Liu, B., Ullman, S., Jadbäck, I., \& Engström, K. (2016). Children's quality of life based on the KIDSCREEN-27: child self-report, parent ratings and child-parent agreement in a Swedish random population sample. PLoS One, 11(3), e0150545e0150545. https://doi.org/10.1371/journal.pone.0150545.

35. Hagen, K. A., Hilsen, M., Kallander, E. K., \& Ruud, T. (2019). Health-related quality of life (HRQoL) in children of ill or substance abusing parents: examining factor structure and sub-group differences. Quality of Life Research, 28(4), 1063-1073. https:// doi.org/10.1007/s11136-018-2067-1.

36. Cohen, J. (1992). A power primer. Psychological Bulletin, 112(1), 155.

37. Corp, I. B. M. (2016). IBM SPSS Statistics for Windows, Version 24.0. Armonk, NY: IBM Corp.

38. R Core Team (2019) R: A language and environment for statistical computing. R Foundation for Statistical Computing, Vienna, Austria. Available at: https://www.R-project.org/.

39. van Buuren, S., \& Groothuis-Oudshoorn, K. (2011). Mice: multivariate imputation by chained equations in R. Journal of Statistical Software, 45(3), 1-67.

40. Rosseel, Y. (2012). Lavaan: an R package for structural equation modeling. Journal of Statistical Software, 48(2), 1-36.

41. OECD. (2011). How's life?: measuring well-being. Paris: OECD Publishing. https://doi.org/10.1787/9789264121164-en.

42. Conger, D., \& Finkelstein, M. J. (2003). Foster care and school mobility. Journal of Negro Education, 72, 97-103.

43. Hiller, R. M., \& Clair, M. C. S. (2018). The emotional and behavioural symptom trajectories of children in long-term out-of-home care in an English local authority. Child Abuse \& Neglect, 81, 106-117.

44. van Ginkel, J. R., Linting, M., Rippe, R. C. A., \& van der Voort, A. (2019). Rebutting existing misconceptions about multiple imputation as a method for handling missing data. Journal of Personality Assessment. https://doi.org/10.1080/00223891.2018.1530680.

Publisher's Note Springer Nature remains neutral with regard to jurisdictional claims in published maps and institutional affiliations. 